\section{Inheritance of root distribution in common bean and selection strategy}

\author{
Rita Carolina de Melo ${ }^{1 *}$, Nicole Trevisani ${ }^{1}$, Sabrina Cristina \\ Corrêa ${ }^{1}$, Altamir Frederico Guidolin ${ }^{1}$, and Jefferson Luís \\ Meirelles Coimbra ${ }^{1}$
}

\begin{abstract}
The objective was to determine the predominant genetic inheritance in the trait root distribution in common bean and define the selection strategy. An experiment involving 40 genetic constitutions (segregating and fixed populations), was developed during the agricultural years 2014/15 and 2015/16. The experiment was arranged in a Federer's augmented block design with 3 replicates. The root distribution was evaluated by Bohm method. Estimates of mean contrasts between the $F_{4}$ progenies and their parents did not reveal any significant differences in any comparison. The generations $F_{5}$ and $F_{6}$ presented the same behavior. The distribution of the component of the additive genetic variance was similarly conducted for the segregating generations. Thus, since the predominant inheritance of the root distribution is additive, the selection of this trait is recommended to be performed at the end of the breeding program.
\end{abstract}

Keywords: Phaseolus vulgaris L., additivity, homozygous loci, contrasts, selection.

\section{INTRODUCTION}

The development of a prominent root system is considered one of the major mechanisms of adaptation to abiotic stresses (Lynch 2007, Bishopp and Lynch 2015). Bean breeding programs developed worldwide report the relevance of roots in the search for drought tolerance (Urrea et al. 2009, Assefa et al. 2015) and efficient use of nutritional resources (Mendes et al. 2015, DoVale et al. 2013, Miguel et al. 2013). Water stress and soil infertility are the greatest yield limitations globally. The development of crops with root systems that can capture more water and nutrients would directly improve food security and economic development in poor nations and would also improve the sustainability of agriculture in rich nations by reducing reliance on intensive fertilization and irrigation. The latter consume large amounts of energy and natural resources and cause environmental pollution (Bishopp and Lynch 2015). However, since the phenotyping of this trait is expensive, research works on genetic inheritance are still scarce and incipient (Toaldo et al. 2013, De Melo et al. 2016).

Advances in research on the genetic control of root distribution are restricted to laboratory tests or highly controlled environmental conditions, such as the identification, cloning and characterization of QTL Dro1 (DEEPER ROOTING 1) in rice (Uga et al. 2013) and identification of Pup1 locus for tolerance to phosphorus deficiency in rice (Gamuyao et al. 2012). Particularly, the lack of knowledge
Crop Breeding and Applied Biotechnology 18: 373-381, 2018 Brazilian Society of Plant Breeding. Printed in Brazil http://dx.doi.org/10.1590/1984$70332018 v 18 n 4 a 56$ (n) 
about the effects of the genotype and its interaction with the environment on phenotype makes it difficult to develop strategies to improve productivity and agricultural sustainability (Burridge et al. 2016, Topp et al. 2016). There is a lack of information to help breeders define how and when the selection for the trait should be effectively performed. For such, it is essential to carry out studies on the predominant inheritance of root distribution, under real cultivation conditions.

The main types of inheritance expected in a given trait depend on the average degree of dominance (Vencovsky et al. 2012). The following allelic interactions may occur: i) the performance of the progeny is similar to the average performance of the parents, given the additive variation and ii) the performance of the progeny is discrepant to the parents' average performance, given the non-additive variation (Fehr 1987). The selection of any trait is based on the quantification and interpretation of these components (Zemolin et al. 2016). The knowledge about the prevalence of a certain component of the genetic variance in the expression of root distribution is essential for the successful selection of genotypes adapted to low input agriculture (Burridge et al. 2016).

Therefore, the present study aimed to determine the predominant genetic inheritance of root distribution in common bean and define the selection strategy to improve this trait.

\section{MATERIAL AND METHODS}

\section{Genetic constitutions assessed}

Eight genotypes of common bean were evaluated as to the root distribution: six of them were accessions from the Bean Active Germplasm Bank (BAF 07, BAF 09, BAF 35, BAF 44, BAF 50 and BAF 63) from different parts of the state of Santa Catarina, and two are commercial cultivars (Perola and IPR Uirapuru). Four superior genotypes from the eight evaluated were chosen for the distribution of the root system, as follows: BAF 07, BAF 09 and IPR Uirapuru from the black commercial group, and BAF 50 from the Carioca commercial group (Figure 1).

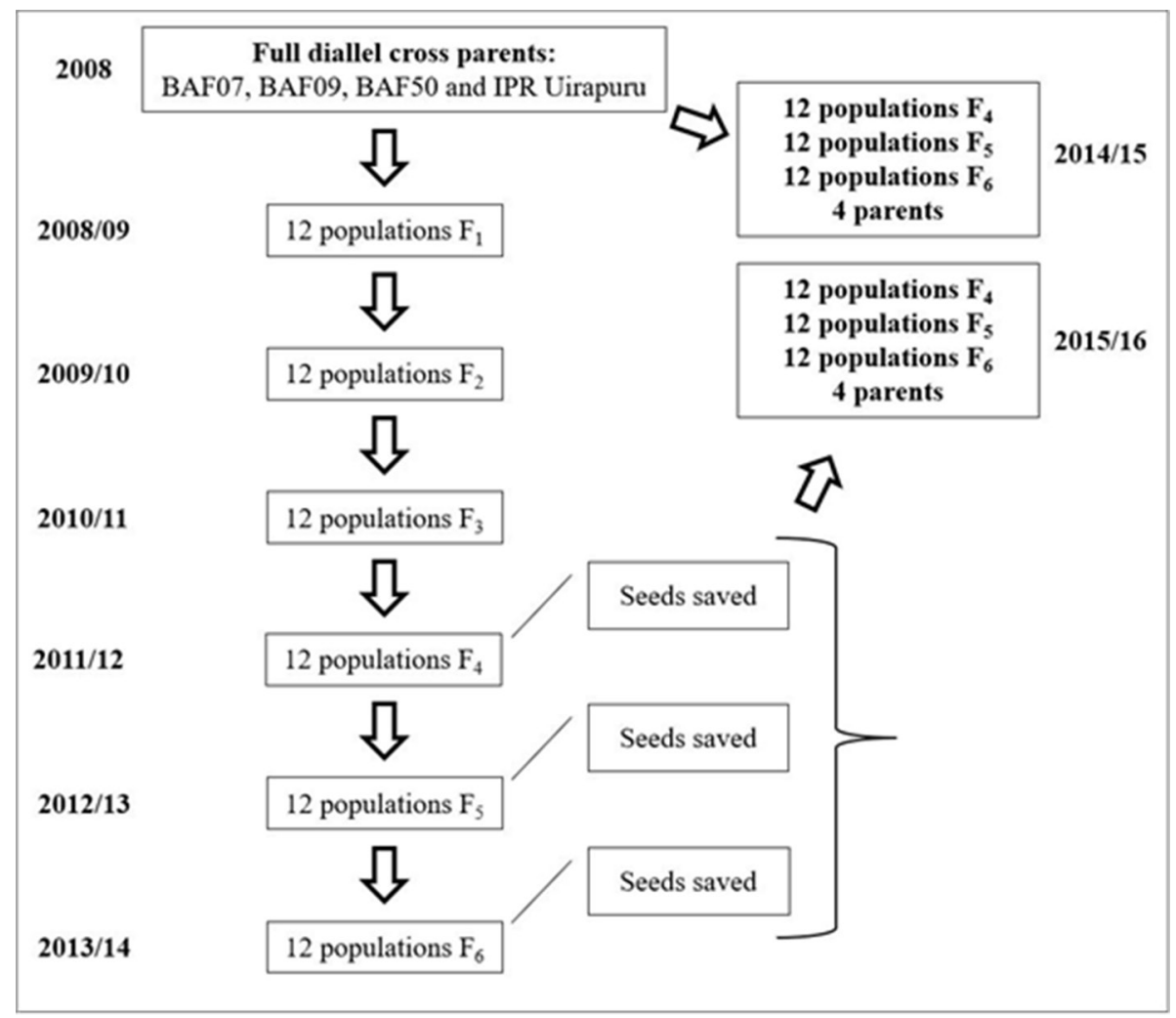

Figure 1. Scheme for obtaining the fixed and segregating populations evaluated in the present study. 
The selected genotypes were crossed in a complete diallel scheme to obtain $F_{1}$ hybrids and their reciprocals. In the evaluation of the first segregating generation $\left(F_{2}\right)$, the best plants were selected for the agronomic traits, forming a sample of the genotypic frequency of each population.

After successive generations of self-pollination, the segregating populations $F_{4}, F_{5}$ and $F_{6}$ were obtained from the crosses and reciprocals: BAF07_BAF09, BAF07_BAF50, BAF07_Uira, BAF09_BAF07, BAF09_BAF50, BAF09_Uira, BAF50_ BAF07, BAF50_BAF09, BAF50_Uira, Uira_BAF07, Uira_BAF09 e Uira_BAF50 which totaled 36 segregating populations. The 36 segregating populations and 4 parents (BAF07, BAF09, BAF50 and IPR Uirapuru) had their seeds saved and were conducted in two agricultural years (2014/15 and 2015/16), as shown in Figure 1.

\section{Location and experimental design}

The experiment was conducted in the experimental field of the Institute of Molecular Breeding and Genetics of the University of the State of Santa Catarina (UDESC) Brazil, State of Santa Catarina, Lages (lat 27 48' S, long 50 19' W, alt $930 \mathrm{~m}$ asl). According to Koppen, the site weather is classified as temperate $\mathrm{cfb}$ (moist mesothermal and mild summer). The soil at the study site is classified as Inceptisol Udepts Humudepts, with a moderate A horizon, clayey texture and undulating relief.

The experiment was arranged in Federer augmented block design with three replicates. In this design, four common treatments (parents) and 36 regular treatments ( 12 segregating populations in $\mathrm{F}_{4}, \mathrm{~F}_{5}$ and $\mathrm{F}_{6}$ generations) were allocated. The plots were composed of four lines with four meters in length, spaced at $0.45 \mathrm{~m}$. A seeding density of 12 seeds per linear meter was used in the internal and external lines, 2 seeds were used per linear meter (a spacing of $0.5 \mathrm{~m}$ between plants) to allow the visualization of the root system. In the external lines of the plot, two plants were evaluated to the trait.

\section{Assessment of root distribution}

Root distribution was quantified in full bloom by the method of the profile described by Böhm (1979), with some adaptations. The method is considered non-destructive and, therefore, important for evaluating segregating populations. Profiles perpendicular to the sowing line were opened on the outer lines of the experimental unit, $0.05 \mathrm{~m}$ from the plants. The roots were exposed with pointed stems. Next, a rectangle with $0.5 \mathrm{~m}$ of width, $0.3 \mathrm{~m}$ of height, subdivided into 60 squares (with $0.05 \mathrm{~m} \times 0.05 \mathrm{~m}$ edges) was placed on the profile. The root distribution was evaluated by means of a digital image of the profile, at different depths $(0-0.10 \mathrm{~m} ; 0.10-0.20 \mathrm{~m}$ and $0.20-0.30 \mathrm{~m})$, according to a binary system, and presence (1) or absence (0) was attributed in each square.

\section{Statistical analysis and determination of the predominant inheritance}

The analysis of variance was obtained using the SAS (Statistical Analysis System, version 9.2) and the GLIMMIX procedure. The Mixed Generalized Linear Model was used to meet the model assumptions. Since root distribution in this study is a variable that involves counting data, the main objective of the study is defining the scale on which an additive linear model occurs; in the present case, the definition of the binomial scale. The following mathematical model expressed root distribution behavior:

$$
\left.Y_{i j k l m}=\mu+\text { block }_{i}+\text { depth (population*generation*year) }\right)_{j(k l m)}+e_{i j k l m}
$$

Where: $Y_{i j k m}$ - values observed for root distribution in the $i$-th experimental unit in the j-th depth in the k-th population in the l-th generation for the $\mathrm{m}$-th year; $\mu$ - effect of the overall average, block block factor; depth (population*generation*year) ${ }_{j(k \mid m)}$ - fixed effect of the j-th level of the depth factor nested under the interaction of the $\mathrm{k}$-th level of the population factor of the l-th level of the generation factor and $\mathrm{m}$-th level of the year factor and $e_{i j k l m}$ - effect of the experimental error.

Differences between the segregating progenies $\left(F_{4}, F_{5}\right.$ and $\left.F_{6}\right)$ and the parents $\left(P_{1}, P_{2}, P_{3}\right.$ and $\left.P_{4}\right)$ were determined from non-orthogonal mean contrasts to test the hypotheses for the genetic inheritance prevailing in the trait root distribution. In addition, the effect of the agricultural years on the trait was determined according to the same hypothesis test statistics. 


\section{RESULTS AND DISCUSSION}

The trait root distribution revealed significant differences in the causes of controlled variation (Table 1). This trait is probably variable for the levels of the nested depth factor under the interactions of the levels of the year, population and generation factor. The assessment of the segregating populations in the same agricultural year, in repeated years, provides subsidies for breeders to define the predominant inheritance of a particular trait, besides preventing the effect of the segregating generation from being mistaken by the random effect of each agricultural year (De Melo et al. 2016).

The genetic control of any trait can be defined by the comparative evaluation of the segregating progenies and their parents (pure and contrasting), clearly distinguishing the genetic effects from the environmental effects. Thus, comparisons between the genetic value of the segregating populations and their respective parents were shown in Table 2. The transformed estimates of the average differences between the $F_{4}$ progenies and their respective parents showed no significant differences in any of the comparisons conducted. All segregating populations in the $\mathrm{F}_{4}$ generation presented performance similar to that of the average of the parents, regardless of the agricultural year. Thus, the genetic variation can be attributed to genes with additive effects (Mukamuhirwa et al. 2015).

With only three generations of self-pollination, the proportion of loci in homozygosis increased significantly to the point of equating to the homozygous loci of the parents (BAF07, BAF09, BAF50 and Uirapuru). In the $\mathrm{F}_{4}$ generation, for example, considering only one gene in a diploid species whose characteristic expresses complete dominance, $87.5 \%$ of the loci are expected to be homozygous (Fehr 1987). The results support this hypothesis. However, it is known that this trait is governed by numerous quantitative genes (Uga et al. 2013) and that under this condition, the number of self-pollinations to promote the expected proportion of loci in homozygosis is infinitely higher, unless the genetic inheritance is predominantly additive.

One of the most important characteristics of additivity is the fact that the average of the offspring of any individual or group of individuals is equal to that of this individual. In other words, the average of the offspring can be predicted by the average of the parents or by the phenotypic value of the self-pollinationed individual (Chelaifa et al. 2013). When this type of interaction prevails, selection becomes easier, since when one individual or group of higher individuals is selected, a higher offspring is obtained as well. Since root distribution is a trait difficult to quantify, the allelic interaction of the additive type may facilitate the selection of better genetic constitutions.

Similarly to all species, the growth and development of the root system in common bean are discontinuous through the soil depths. The importance of the root system varies in each layer (Lynch 2011). Its importance is related to the superficial development of roots and the respective nutrient uptake through fertilization (Ramaekers et al. 2010). Besides, its importance is related to better absorption of water and nutrients in depth (Zadraznik et al. 2013). Therefore, it is fundamental to assess the genetic constitutions at each depth, $0-0.10 \mathrm{~m}$ (Figure 2) and $0.10-0.20 \mathrm{~m}$ (Figure 3).

The genetic behavior of the fixed $\left(P_{1}\right.$ and $\left.P_{2}\right)$ and segregating $\left(F_{4}, F_{5}\right.$ and $\left.F_{6}\right)$ populations at the depth of $0-0.10 \mathrm{~m}$, expressed in the original mean scale $\mu 0$, showed results similar to those previously discussed (Figure 2 ). In this figure, each graph presents the progenies compared to the parents over the agricultural years. No significant differences are 
BAF07_BAF09

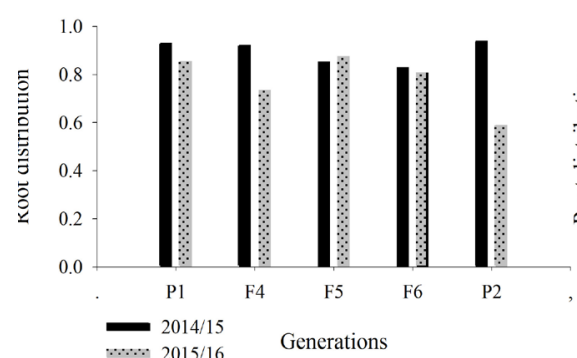

BAF09_BAF07
BAF07_BAF50

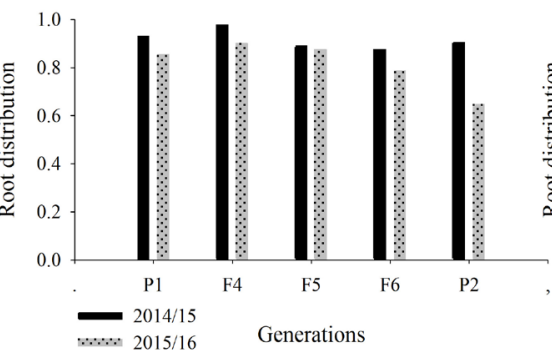

BAF09_BAF50
BAF07_Uirapuru

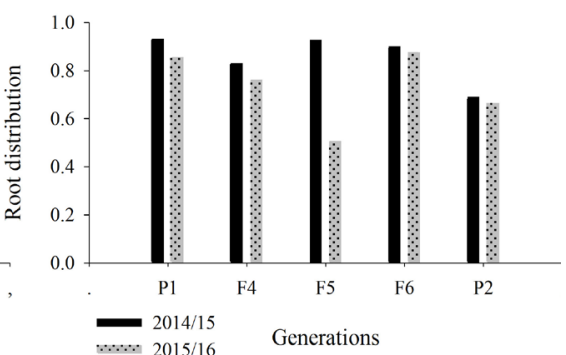

BAF09_Uirapuru
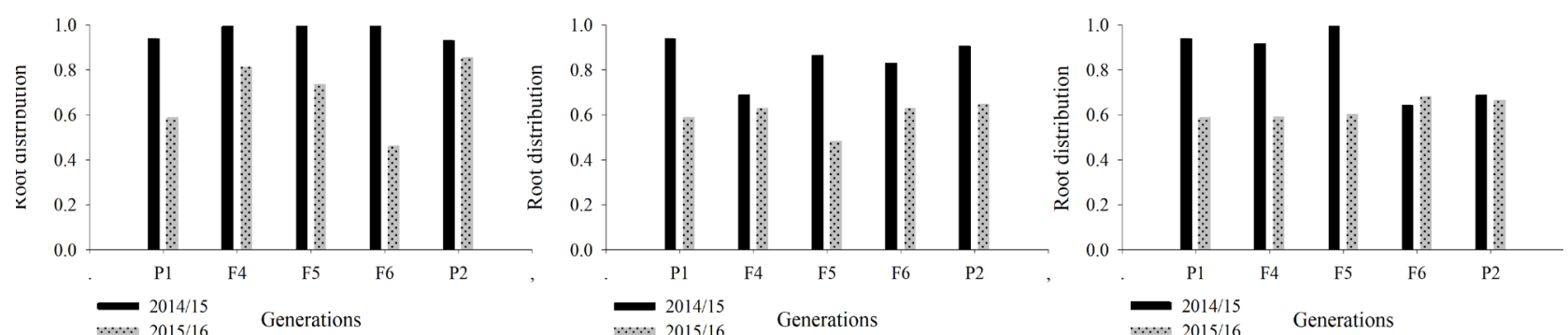

BAF50 BAF07

BAF50_BAF09

BAF50_Uirapuru
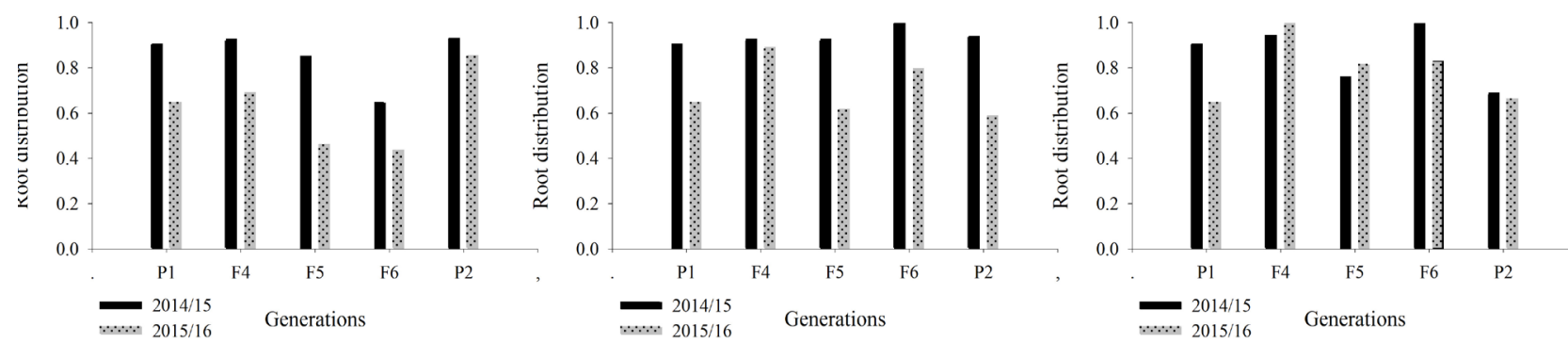

Uirapuru_BAF07

Uirapuru_BAF09

Uirapuru_BAF50
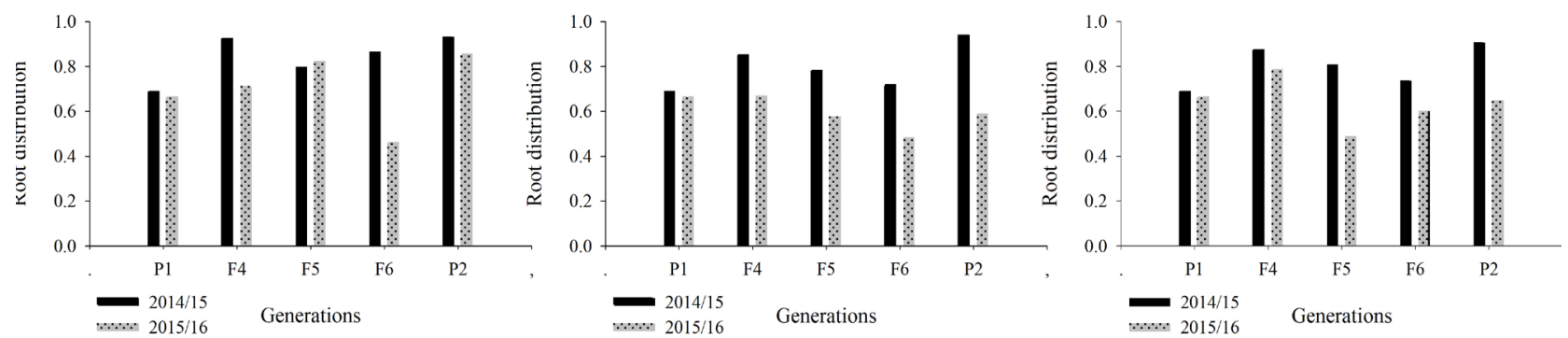

Figure 2. Root distribution (original mean scale $\mu 0$ ) of twelve segregating genetic constitutions and their respective parents ( $P_{1}$ and $P_{2}$ ) at the depth of $0-0.10 \mathrm{~m}$. Estimates obtained for the agricultural years 2014/15 (black bar) and 2015/16 (gray bar) for each genetic constitution. 
BAF07_BAF09

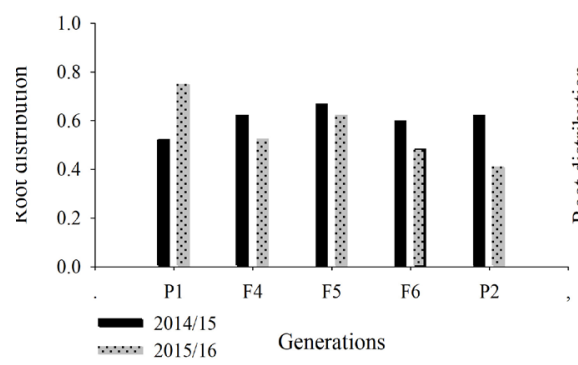

BAF09_BAF07

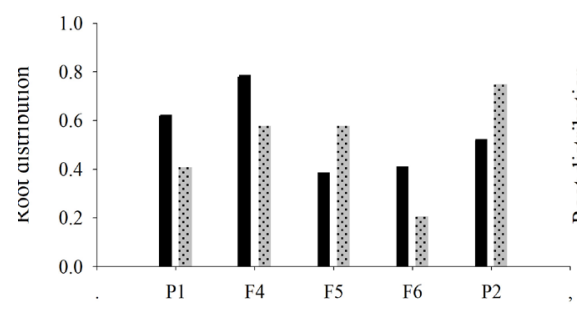

$2014 / 15$
$2015 / 16$

BAF50_BAF07

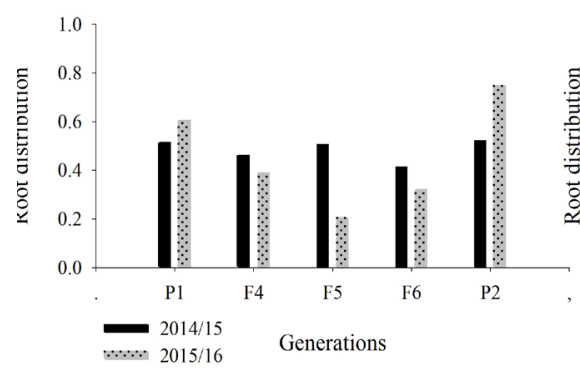

Uirapuru_BAF07

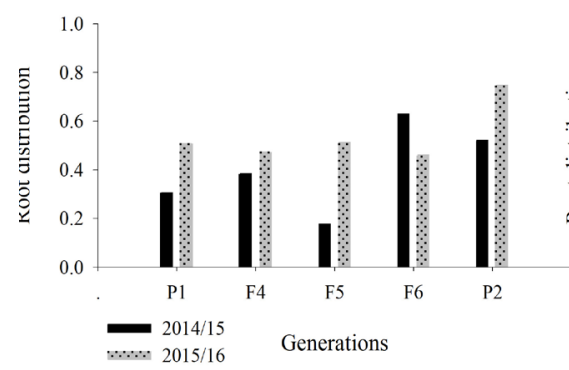

BAF07_BAF50

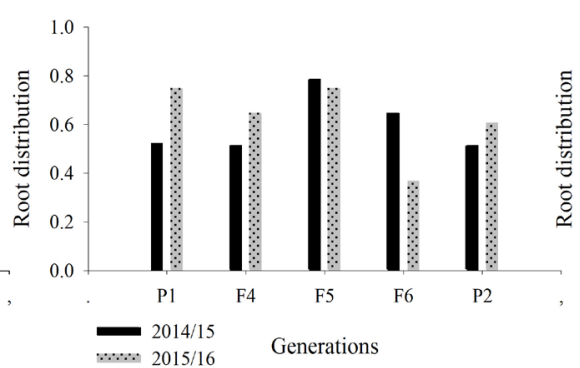

BAF09_BAF50

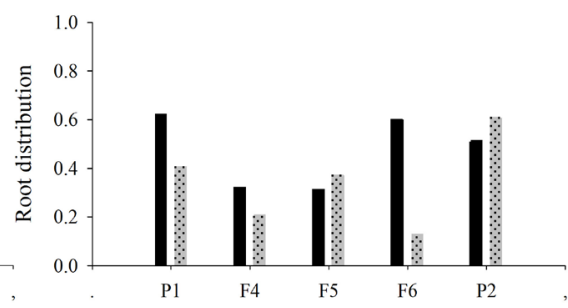

${ }_{2015 / 16}^{2015}$

Generations

BAF50_BAF09

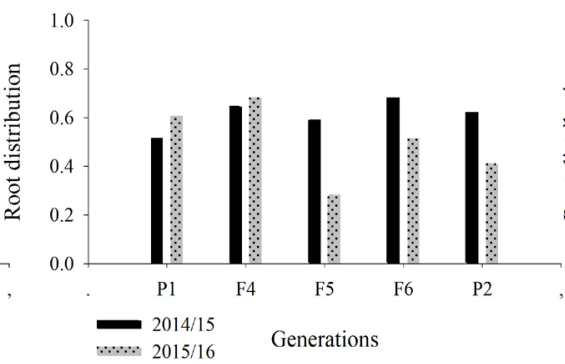

Uirapuru_BAF09

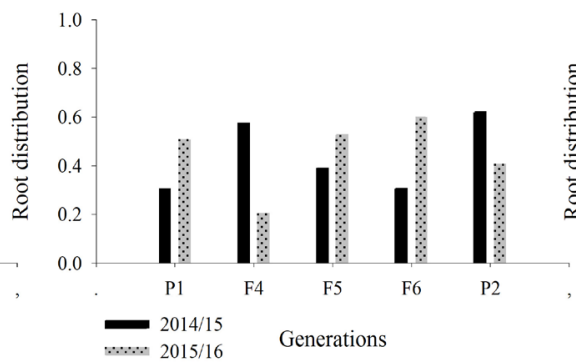

BAF07_Uirapuru

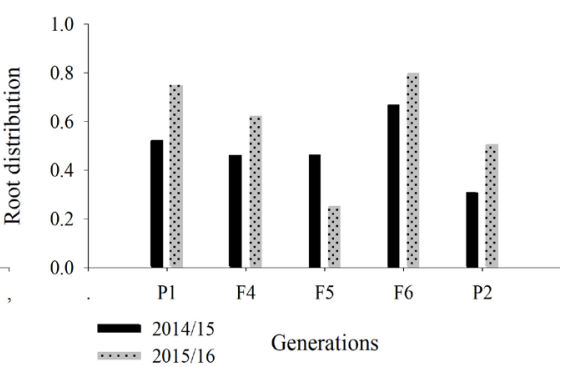

BAF09_Uirapuru

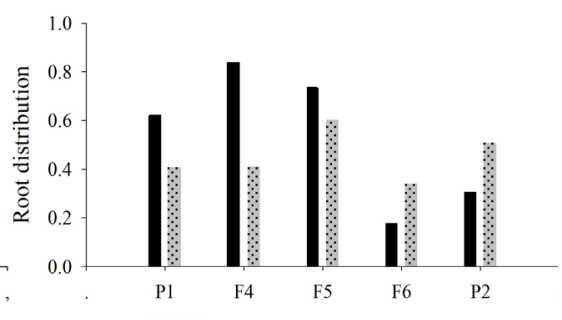

2014/15 Generations

BAF50_Uirapuru

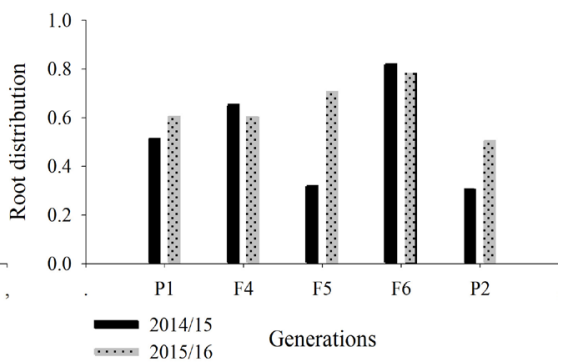

Uirapuru_BAF50

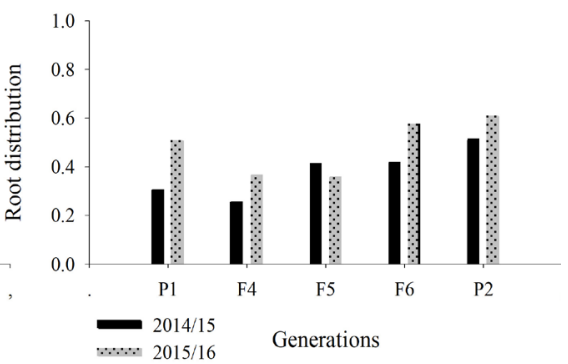

Figure 3. Root distribution (scale of original means $\mu 0$ ) of twelve segregating genetic constitutions and their respective parents ( $P_{1}$ and $P_{2}$ ) at the depth of $0.10-0.20$ m. Estimates obtained for the agricultural years 2014/15 (black bar) and $2015 / 16$ (gray bar) for each genetic constitution. 
observed either between the average of the parents and the respective $\mathrm{F}_{4}$ progeny in any of the agricultural years assessed. The performance of the segregating progenies (heterozygotes) was invariably revealed in the average of their parents and their superiority cannot be admitted.

In rare conditions, such as the comparison involving BAF50_BAF09 $\mathrm{F}_{4}, \mathrm{BAF}_{0}$ _UIRA $\mathrm{F}_{4}$ and UIRA_BAF50 $\mathrm{F}_{4}$, the mean root distribution seems to transcend the phenotype of the parents, in crude averages (Figure 2). However, the hypothesis test proves that the differences are not significant, at $5 \%$ probability of error. The progenies mentioned are the crosses with greater divergence, which bring together the black and carioca commercial groups in the same genetic constitution. The same behavior was observed for all genetic constitutions evaluated. Throughout the segregating generations, increased loci in homozygosis or decreased frequency of heterozygous genotypes naturally led to increased endogamy, which was rapidly achieved through self-pollination (Wright 1949).

Similar results were observed for the depth $0.10-0.20 \mathrm{~m}$ (Figure 3). No $\mathrm{F}_{4}$ progeny revealed behavior different from that of their parents in any agricultural year, although phenotypic oscillations seem to be more usual, compared to the $0-0.10 \mathrm{~m}$ depth. However, phenotypically, the root distribution at this depth is considerably reduced, and the averages do not exceed $0.8(\mu 0)$. The less pronounced root distribution at the lower depths was already expected, due to the uneven growth and positive geotropism of the roots (Lynch 1995). In addition, another factor that reduces root distribution at lower depths is the fact that most breeding programs are performed under optimal conditions of cultivation or high input environments (fertilized and irrigated areas), which induces the selection of plants with denser root system in the basal or superior soil layer (Lynch 2007).

Now that the behavior of the $\mathrm{F}_{4}$ segregating progenies in relation to the parents has been clarified, it must be verified whether the inferences can be valid for the other generations, so as to determine the prevailing genetic control of this trait (Table 3). The contrast of transformed means between the different generations did not reveal significant differences. The genotypic performance was similar, regardless of the number of Throughout the segregating generations, increased loci in homozygosis or decreased frequency of heterozygous genotypes naturally led to increased endogamy, which was rapidly achieved through self-pollinations (three, four or five) and their respective genetic consequences for the heterozygous loci and restoration of the homozygous condition, as well as the segregating populations involved and their origins. Analogously, the $F_{5}$ and $F_{6}$ generations showed the same behavioral trend and no statistical differences. The distribution of the additive genetic variance component occurred similarly and evenly among the segregating generations, in all populations assessed.

The only significant differences observed among the populations of the respective study are due to their different commercial groups, such as BAF50_Uira $\mathrm{F}_{6}$ (carioca) versus BAF09_BAF07 $\mathrm{F}_{6}$ (black). The difference can be explained by the genetic divergence between the parents involved in these crosses, which results in increased hybrid vigor. The progeny BAF50_Uira $\mathrm{F}_{6}$ has the parent BAF50 (carioca commercial group) in its genetic constitution and the parent IPR Uirapuru (black commercial group). On the other hand, BAF09_BAF07 $\mathrm{F}_{6}$ came from parents of the black commercial group. Crosses involving highly divergent genetic constitutions (with contrasting alleles in the same locus) result in progenies with higher proportion of heterozygous loci - thus becoming the dominance variance component (Toaldo et al. 2013).

The study on the distribution of genetic variance over segregating generations that brings together the distinct generations in the same agricultural year (environment) is advantageous. The repetition of the same assay may be even more interesting to express the actual genetic behavior of the trait studied and determine the predominant mode

Table 3. Estimates of non-orthogonal contrasts in the transformed scale $(\mu \mathrm{T})$ for the mean difference between progenies at different segregation levels $\left(F_{4}, F_{5}\right.$ and $\left.F_{6}\right)$ for the trait root distribution. Estimates obtained for the agricultural year 2014/15

\begin{tabular}{lcc}
\hline \multirow{2}{*}{ Genetic constitution } & \multicolumn{2}{c}{ Estimates between segregating generations ${ }^{\mathbf{a}}$} \\
\cline { 2 - 3 } & $\mathbf{F}_{4}$ vs $\mathbf{F}_{5}$ & $\mathbf{F}_{5}$ vs $\mathbf{F}_{6}$ \\
\hline BAF07_BAF09 & -0.69 & 0.75 \\
BAF07_BAF50 & -2.09 & 0.18 \\
BAF07_Uirapuru & 0.54 & -1.22 \\
BAF09_BAF07 & 14.03 & -12.17 \\
BAF09_BAF50 & 0.08 & -1.16 \\
BAF09_Uirapuru & -0.29 & 15.29 \\
BAF50_BAF07 & -0.50 & 13.88 \\
BAF50_BAF09 & -1.53 & -0.57 \\
BAF50_Uirapuru & 1.21 & -0.63 \\
Uirapuru_BAF07 & 13.30 & -14.75 \\
Uirapuru_BAF09 & 1.65 & 12.60 \\
Uirapuru_BAF50 & -13.08 & 1.05
\end{tabular}
$H_{0}: \mu_{1}-\mu_{2}=0 . H_{A}: \mu_{1}-\mu_{2} \neq 0$. The null hypothesis $H_{0}$ tested by the $t$ test at 0.05
probability. 


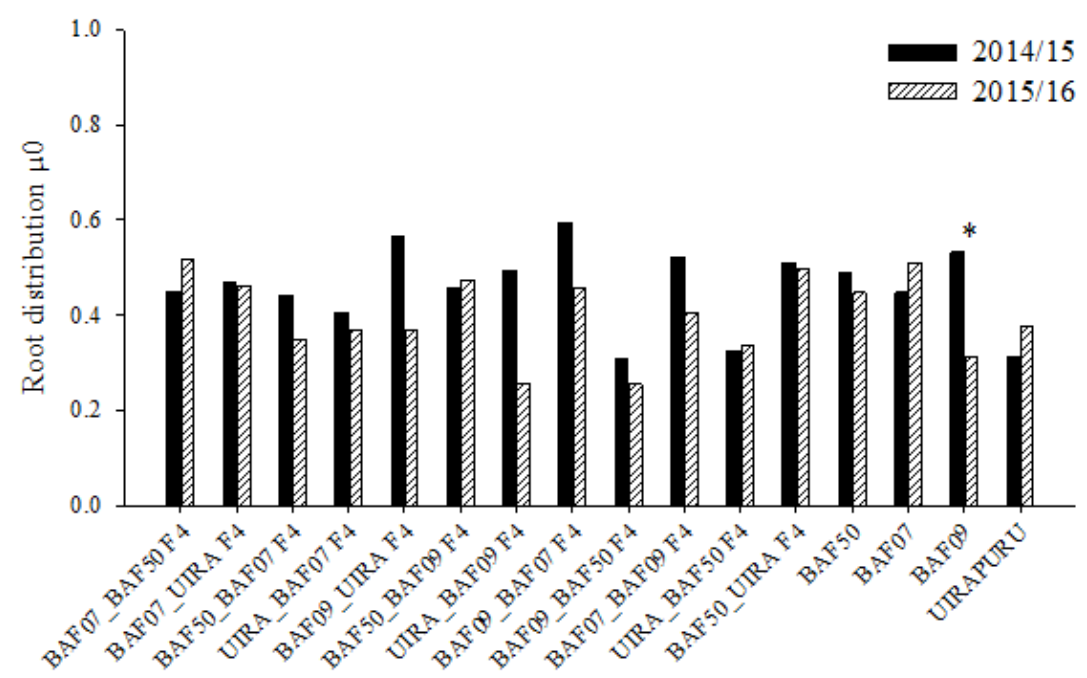

Figure 4. Original means $(\mu 0)$ of the trait root distribution for each $F_{4}$ segregating population and parents. Estimates of the mean difference between the agricultural years 2014/15 (black bar) and 2015/16 (dashed white bar). * Significant at 0.05 probability of type I error by the t test. $\mathrm{H}_{0}: \mu_{1}-\mu_{2}=0 . \mathrm{H}_{\mathrm{A}}: \mu_{1}-\mu_{2} \neq 0$.

of inheritance (Valentini et al. 2011). Figure 4 shows the original means of the root distribution for each $\mathrm{F}_{4}$ segregating population and the parents, in the different agricultural years, and the significant difference between the transformed means (if there is any) of the genetic constitutions in the different years. It was possible to verify that only the parent BAF09 presented a discrepant behavior between the evaluation years - 2014/15 and 2015/16. This fact indicates that the genetic breeding of this trait can be facilitated, since the environment was not able to mask the genetic behavior of the trait. The trait root distribution is insensitive to the intrinsic variations of the agricultural year. Therefore, the determination of the component of genetic variance and the selection of the trait can be facilitated. In other words, the trait studied reveals high expressiveness and can be selected by breeders, regardless of the agricultural year.

Comparisons between the means of the segregating progenies and of their respective parents did not reveal significant differences, regardless of the agricultural year and the genetic constitution itself. This reveals a strong characteristic of the additive-type inheritance, in which the performance of the segregating progenies resumes the average of their parents. In other words, the homozygous condition of the genes is restored due to the natural process of Throughout the segregating generations, increased loci in homozygosis or decreased frequency of heterozygous genotypes naturally led to increased endogamy, which was rapidly achieved through self-pollination and distribution of genetic variance (Fehr 1987). Previous studies conducted by Toaldo et al. (2013) and De Melo et al. (2016) found that the $F_{2}$ and $F_{3}$ hybrid populations showed hybrid vigor or heterosis, compared to their parents. However, due to the lack of economically feasible alternatives to obtain commercial hybrids in beans (Ramalho et al. 1993), the breeding program must advance the segregating generations to obtain a fixed population. These results corroborate the findings of De Melo et al. (2016), who assessed the same segregating populations separately, one in each crop year. The studies provide subsidies for the effective selection of the trait root distribution in common bean.

The present study revealed that, since the predominant mode of inheritance in the trait root distribution is additive, effective selection of the best genetic constitutions should be conducted at the end of the breeding program, rather than at early generations. Otherwise, genetic progress would be unsatisfactory. In addition, the conductance of segregating populations aiming to achieve faster results should be carried out by the SSD (Single Seed Descent) method. This method allows advancing more than one generation per year and performing selection only in advanced generations. This favors genetic progress, since selection can be conducted without the interference of non-additive effects.

\section{ACKOWLEDGEMENTS}

To the Conselho Nacional de Desenvolvimento Científico e Tecnológico (CNPq), Coordenação de Aperfeiçoamento 
de Pessoal de Nível Superior (CAPES) and Fundação de Apoio à Pesquisa Científica e Tecnológica do Estado de Santa Catarina (FAPESC) for the scholarship granting and financial support provided to the present work.

\section{REFERENCES}

Assefa T, Wu J, Beebe SE, Rao IM, Marcomin D and Claude RJ (2015) Improving adaptation to drought stress in small red common bean: phenotypic differences and predicted genotypic effects on grain yield, yield components and harvest index. Euphytica 203: 477-489.

Bishopp A and Lynch JP (2015) The hidden half of crop yields. Nature Plants 1: 1-2.

Böhm W (1979) Methods of studying root systems. Springer, Berlin, 188p.

Burridge J, Jochua CN, Bucksch A and Lynch JP (2016) Legume shovelomics: High-throughput phenotyping of common bean (Phaseolus vulgaris L.) and cowpea (Vigna unguiculata subsp, unguiculata) root architecture in the field. Field Crops Research 192: 21-32.

Chelaifa H, Chague V, Chalabi S, Mestiri I, Arnaud D, Deffains D, Lu Y, Belcram H, Huteau V, Chiquet J, Coriton O, Just J, Jahier J and Chalhoub B (2013) Prevalence of gene expression additivity in genetically stable wheat allohexaploids. New Phytologist Journal 197: 730-736.

De Melo RC, Schmit R, Cerutti PH, Guidolin AF and Coimbra JLM (2016) Genetic variation in the trait root distribution over segregating generations of common bean. Euphytica 207: 665-674.

DoVale JC, Maia C, Fristche-Neto R, Miranda GV and Cavatte PC (2013) Genetic responses of traits relationship to components of nitrogen and phosphorus use efficiency in maize. Acta Scientiarum. Agronomy 35: 31-38.

Fehr WR (1987) Principles of cultivars development. Macmillan, New York, 536p.

Gamuyao R, Chin JH, Pariasca-Tanaka J, Pesaresi P, Catausan S, Dalid C, Slamet-Loedin I, Tecson-Mendoza EM, Wissuwa M and Heuer S (2012) The protein kinase Pstol1 from traditional rice confers tolerance of phosphorus deficiency. Nature 488: 535-539.

Lynch JP (1995) Root architecture and plant productivity. Plant Physiology 109: 7-13.

Lynch JP (2007) Roots of the second green revolution. Australian Journal of Botany 55: 493-512.

Lynch JP (2011) Root phenes for enhanced soil exploration and phosphorus acquisition: tools for future crops. Plant Physiology 156: 1041-1049.

Mendes FF, Guimarães LJM, Guimarães CT, Souza JC, Guimarães PEO and Parentoni SN (2015) Genetic control of traits related to phosphorus use efficiency in tropical maize. Crop Breeding and Applied Biotechnology 15: 59-65.

Miguel MA, Widrig A, Vieira RF, Brown KM and Lynch JP (2013) Basal root whorl number: a modulator of phosphorus acquisition in common bean (Phaseolus vulgaris L.). Annals of Botany 112: 973-982.

Mukamuhirwa F, Tusiime G and Mukankusi MC (2015) Inheritance of high iron and zinc concentration in selected bean varieties. Euphytica 205: 349-360.

Ramaekers L, Remans R, Rao IM, Blair MW and Vanderleyden J (2010) Strategies for improving phosphorus acquisition efficiency of crop plants. Field Crops Research 117: 169-176.

Ramalho MAP, Santos JB and Zimmermann MJO (1993) Genética quantitativa em plantas autógamas: aplicação ao melhoramento do feijoeiro. UFG, Goiânia, 271p.

Toaldo D, Morais PPP, Battilana J, Coimbra JLM and Guidolin AF (2013) Selection in early generations and the occurrence of heterosis for the character root distribution. Euphytica 190: 335-344.

Topp CN, Bray AL, Ellis NA and Liu Z (2016) How can we harness quantitative genetic variation in crop root systems for agricultural improvement? Journal of Integrative Plant Biology 58: 213-225.

Uga $Y$, Sugimoto $K$, Ogawa S, Rane J, Ishitani M, Hara N, Kitomi $Y$, Inukai $\mathrm{Y}$, Ono K, Kanno N, Inoue $\mathrm{H}$, Takehisa H, Motoyama R, Nagamura $\mathrm{Y}$, Wu J, Matsumoto T, Takai T, Okuno K and Yano M (2013) Control of root system architecture by DEEPER ROOTING 1 increases rice yield under drought conditions. Nature Genetics 45: 1097-1102.

Urrea CA, Yonts CD, Lyon DJ and Koehler AE (2009) Selection for drought tolerance in dry bean derived from the Mesoamerican gene pool in western Nebraska. Crop Science 49: 2005-2009.

Valentini G, Baldissera JNC, Morais PPP, Stähelin D, Heidemann JC, Stenger F, Elias HT, Guidolin AF and Coimbra JLM (2011) Inheritance of common bean resistance to wilt caused by Curtobacterium flaccumfaciens pv. Flaccumfaciens. Pesquisa Agropecuária Brasileira 46: 1045-1052.

Vencovsky R, Ramalho MAP and Toledo FHRB (2012) Contribution and perspectives of quantitative genetics to plant breeding in Brazil. Crop Breeding and Applied Biotechnology 12: 7-14.

Wright S (1949) The genetical structure of populations. Annals of Eugenics 15: 323-354.

Zadraznik T, Hollung K, Egge-Jacobsen W, Meglic V and Sustar-Vozlic J (2013) Differential proteomic analysis of drought stress response in leaves of common bean (Phaseolus vulgaris L.). Journal of Proteomics 78: 254-272.

Zemolin AEM, Ribeiro ND, Casagrande CR, Silva MJ and Arns FD (2016) Genetic parameters of iron and zinc concentrations in Andean common bean seeds. Scientiarum. Agronomy 38: 439-446.

(cc) EY This is an Open Access article distributed under the terms of the Creative Commons Attribution License, which permits unrestricted use, distribution, and reproduction in any medium, provided the original work is properly cited. 